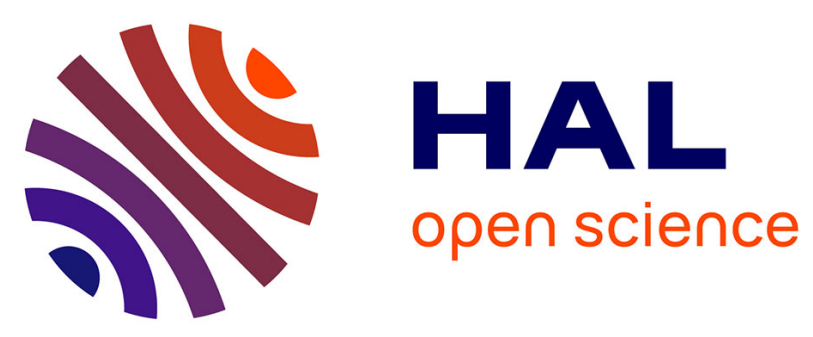

\title{
Amorphous Ge-Sb-Se thin films fabricated by co-sputtering Properties and photosensitivity
}

Tomas Halenkovic, Jan Gutwirth, Petr Nemec, Emeline Baudet, Marion

Specht, Yann Gueguen, Jean-Christophe Sangleboeuf, Virginie Nazabal

\section{- To cite this version:}

Tomas Halenkovic, Jan Gutwirth, Petr Nemec, Emeline Baudet, Marion Specht, et al.. Amorphous GeSb-Se thin films fabricated by co-sputtering Properties and photosensitivity. Journal of the American Ceramic Society, 2018, 101 (7), pp.2877-2887. 10.1111/jace.15453 . hal-01806937

\section{HAL Id: hal-01806937 \\ https://hal-univ-rennes1.archives-ouvertes.fr/hal-01806937}

Submitted on 20 Sep 2018

HAL is a multi-disciplinary open access archive for the deposit and dissemination of scientific research documents, whether they are published or not. The documents may come from teaching and research institutions in France or abroad, or from public or private research centers.
L'archive ouverte pluridisciplinaire HAL, est destinée au dépôt et à la diffusion de documents scientifiques de niveau recherche, publiés ou non, émanant des établissements d'enseignement et de recherche français ou étrangers, des laboratoires publics ou privés. 
DR VIRGINIE NAZABAL (Orcid ID : 0000-0002-0113-3935)

Article type : Article

Amorphous Ge-Sb-Se thin films fabricated by co-sputtering: properties and photosensitivity

Tomáš Halenkovič ${ }^{\ddagger}$, Jan Gutwirth ${ }^{\ddagger}$, Petr Němec ${ }^{\ddagger}$, Emeline Baudet ${ }^{\ddagger}$, Marion Specht ${ }^{\mathbb{I l}}$, Yann Gueguen $^{\mathbb{I}}$, Jean-Christophe Sangleboeuf ${ }^{\mathbb{I}}$ and Virginie Nazabal ${ }^{\ddagger, 8, *}$

$\$$ Department of Graphic Arts and Photophysics, Faculty of Chemical Technology, University of Pardubice, 53210 Pardubice, Czech Republic

§ Institut des Sciences Chimiques de Rennes, UMR-CNRS 6226, Equipe Verres et Céramiques, Université de Rennes 1, 35042 Rennes, France

『I Institut de Physique de Rennes, IPR CNRS 6251, Université de Rennes 1, 35042 Rennes, France

${ }^{*}$ Author to whom correspondence should be addressed. Email: virginie.nazabal@univ-rennes1.fr This article has been accepted for publication and undergone full peer review but has not been through the copyediting, typesetting, pagination and proofreading process, which may lead to differences between this version and the Version of Record. Please cite this article as doi: $10.1111 /$ jace. 15453 
Abstract

Amorphous $\mathrm{Ge}-\mathrm{Sb}-\mathrm{Se}$ thin films were fabricated by a rf-magnetron co-sputtering technique employing the following cathodes: $\mathrm{GeSe}_{2}, \mathrm{Sb}_{2} \mathrm{Se}_{3}$ and $\mathrm{Ge}_{28} \mathrm{Sb}_{12} \mathrm{Se}_{60}$. The influence of the composition, determined by energy-dispersive X-ray spectroscopy, on the optical properties was studied. Optical properties were analyzed based on variable angle spectroscopic ellipsometry and UV-Vis-NIR spectrophotometry. The results show that the optical bandgap range 1.35-2.08 eV with corresponding refractive index ranging from 3.33 to 2.36 can be reliably covered. Furhermore, morphological and topographical properties of selenide sputtered films studied by scanning electron microscopy and atomic force microscopy showed a good quality of fabricated films. In addition, structure of the films was controlled using Raman scattering spectroscopy. Finally, irreversible photo-induced changes by means of change of optical bandgap energy and refractive index of co-sputtered films were studied revealing the photobleaching effect in Ge-rich films when irradiated by near-bandgap light under Ar atmosphere. The photobleaching effect tends to decrease with increasing antimony content.

\section{Introduction}

Amorphous chalcogenides, non-crystalline materials based on the elements of chalcogens (S, Se and Te) have been extensively studied for last several decades. Low phonon energy, broad transmission window, large refractive index and photosensitivity make these materials attractive in the field of photonics, optical phase-change memories, solar cells etc. [1-3]. Moreover, they have tremendous potential in ultrafast all-optical signal processing due to a third order nonlinearities between two to three orders of magnitude greater than that of silica [4]. 
Due to the presence of arsenic in classical chalcogenide glasses $\left(\mathrm{As}_{2} \mathrm{~S}_{3}, \mathrm{As}_{2} \mathrm{Se}_{3}\right)$, which is toxic in its elemental form, arsenic-based non-crystalline chalcogenides are supposed to be environmentally improper for some applications. Considering that germanium can be an alternative glass network former and with respect to required excellent transparency in mid-IR, large (non)linear refractive index and adequate glass-forming ability, the Ge-Se system seems to be advantageous in comparison with Ge-S or Ge-Te ones [5]. Moreover, in contrast with arsenicbased amorphous chalcogenides, four-fold coordinated germanium atoms spatially sustain the glass network resulting in its increased rigidity, higher glass transition temperature $\left(T_{g}\right)$, strength and hardness of these materials [1].

Covalent glasses of ternary Ge-As-Se and Ge-Sb-Se systems have been recently widely studied due to a large glass-forming region and good mechanical and physical properties when compared with classical binary chalcogenides. Although the Ge-As-Se system is particularly attractive due to its greater glass-forming region compare to $\mathrm{Ge}-\mathrm{Sb}-\mathrm{Se}$ system, the introduction of antimony provides higher polarizability increasing (non)linear refractive index and reduction in photosensitivity [6], representing an interesting option for nonlinear optics [7-9]. Last but not least, improved shaping ability of Ge-Sb-Se glasses allows fabrication of fibers or thin films, which are of high importance considering optical sensor development, for instance [10-12]. This is why study of thin films of ternary Ge-Sb-Se system have already attracted the attention of many authors [13-18].

It is well known that the exposure to the light or other radiation that excites electron-hole pairs, enables to produce some structural changes in chalcogenide glasses and amorphous films. Lightinduced effects in amorphous chalcogenides involve changes in density, hardness, elastic constants, optical properties, electronic transport properties or chemical solubility $[2,19,20]$. The 
shift in the fundamental short-wavelength absorption edge with the corresponding change of optical bandgap energy and refractive index belong to the most important photo-induced phenomena in these materials extensively studied since the early 1970s. De Neufville et al. showed that the red-shift of the absorption edge (photodarkening - PD) of annealed films by bandgap irradiation may be somehow restored by consequent annealing at $\sim T_{\mathrm{g}}$ indicating the reversible optical changes in evaporated and sputtered $\mathrm{As}_{2} \mathrm{Se}_{3}$ or in evaporated $\mathrm{As}_{2} \mathrm{~S}_{3}$ annealed films. In contrast, both as-deposited $\mathrm{As}_{2} \mathrm{Se}_{3}$ and $\mathrm{As}_{2} \mathrm{~S}_{3}$ films exhibit irreversible photo-induced changes [21]. On the other hand, Ge-based chalcogenides exhibit reversible blue-shift in the absorption edge (photobleaching - PB) and irreversible PB in annealed and as-deposited films, respectively [22]. Regarding the different behavior observed between annealed and as-deposited films whatever the selected physical vapor deposition (PVD) method, it can be assumed that a large number of stabilization mechanisms occur during the irradiation of as-deposited films. These include photo-polymerization (accompanied by void collapsing), homo-to-heteropolar bond interchange, and photo-enhanced vaporization on air [2, 23]. Breaking of homopolar bonds ("wrong bonds") followed by the formation of more favorable heteropolar bonds is believed to be responsible for intrinsic photo-darkening in As-based and photo-bleaching in Ge-based chalcogenide glasses [24]. These structural changes in selenides can be described by following equation $[25,26]$ :

The reduction of homopolar bonds density occurs also during the annealing process [26]. In Gebased chalcogenides, presence of oxygen and water vapor during the irradiation can lead to lightinduced oxidation (photo-oxidation) [25, 27]. According to Tichý et al. the increase in optical gap probably reflects the decrease in localized states density at the band edges and an increase of the 
'mean' bond energy caused by the formation of strong $\mathrm{Ge}-\mathrm{O}$ bonds [27]. It has to be noted that intrinsically photostable amorphous chalcogenides were reported in Ge-As-Se system [28, 29].

Recently, the photosensitivity of pulsed laser deposited (PLD) Ge-Sb-Se films was studied by Olivier et al. They find out that the irradiation with energy close to bandgap of as-deposited thin films leads to the PB effect. They also reported that this phenomenon seems to decrease when increasing antimony content [18].

PVD techniques such as thermal evaporation, PLD or radio-frequency (rf) sputtering are generally suitable for the fabrication of thin chalcogenide films. In detail, growth of $\mathrm{Ge}-\mathrm{Sb}-\mathrm{Se}$ thin films was already reported for thermal evaporation [16], $\mathrm{rf}$ magnetron sputtering $[10,11,16]$ and PLD [18, 30]. Among mentioned methods, rf-sputtering has found its wide use due to its relative simplicity, easy control of the process, often stoichiometric material transfer from target to substrate and the large area coverage [11]. Specifically, rf co-sputtering technique brings advantage of adjustable electrical power ratio applied on individual cathodes which enables to obtain thin films with various compositions making this method cost-effective for compositional dependencies' studies of materials' properties. However, to date only a very few reports deal with the co-sputtering of amorphous chalcogenide thin films [31-34]. These include $\mathrm{Ge}_{2} \mathrm{Sb}_{2} \mathrm{Te}_{5}$ doped by various elements, e.g. bismuth, aluminum or tin [32, 33], but also In-doped $\mathrm{GeSe}_{2}$ [31], and most recently $\mathrm{Sb}(\mathrm{Ge})$-doped $\mathrm{Ge}_{20} \mathrm{Sb}_{15} \mathrm{Se}_{65}$ or $\mathrm{Ge}_{28} \mathrm{Sb}_{12} \mathrm{Se}_{60}$ [34], eventually co-sputtering of $\mathrm{GeSe}_{2}$ and $\mathrm{Sb}[17]$.

Indeed, large variety of amorphous Ge-Sb-Se thin films were fabricated in this work using rf-magnetron co-sputtering employing three cathodes with $\mathrm{GeSe}_{2}, \mathrm{Sb}_{2} \mathrm{Se}_{3}$ and $\mathrm{Ge}_{28} \mathrm{Sb}_{12} \mathrm{Se}_{60}$ sputtering targets. Consequently, optical and structural properties of the films depending on 
chemical composition were investigated through selected spectroscopic and analytical techniques, namely UV-Vis-NIR spectrophotometry, variable angle spectroscopic ellipsometry, scanning electron microscopy with energy-dispersive X-ray analysis, atomic force microscopy and Raman scattering spectroscopy. Finally, photosensitivity of fabricated films under Ar atmosphere was studied.

\section{Experimental procedures}

Selenide films were deposited at a room temperature by conventional $\mathrm{rf}(13.56 \mathrm{MHz})$ magnetron co-sputtering in Ar plasma onto two different substrates - crown glass (Schott BK7) and single crystalline silicon <100>. For depositions, MPE600S (Plassys-Bestek) multi-chamber physical vapor deposition system equipped with confocal sputtering cluster consisting of three cathodes was used. Three 2" targets with following composition were selected: $\mathrm{GeSe}_{2}$ (American Elements Corp., Los Angeles, CA, USA) positioned on cathode 1 (hereinafter referred to $\mathrm{C} 1$ ), $\mathrm{Sb}_{2} \mathrm{Se}_{3}$ (American Elements Corp., Los Angeles, CA, USA) on cathode 2 (C2) and $\mathrm{Ge}_{28} \mathrm{Sb}_{12} \mathrm{Se}_{60}$ (Vitron GmbH., Jena, Germany) on cathode 3 (C3). The sputtering depositions were performed at room temperature. The experimental conditions, held constant throughout, were as follows: background pressure $\leq 5 \times 10^{-7}$ mbar, Ar working pressure $5 \times 10^{-3}$ mbar, Ar flow rate $75 \mathrm{sscm}$, with substrate holder rotation. For each sputtering deposition, the composition of the selenide thin films was modified by the individual tuning of the rf power (up to $15 \mathrm{~W}$ ) on the three cathodes (Table I).

A scanning electron microscope (SEM) with an energy-dispersive X-ray analyzer (EDS, JSM 6400-OXFORD Link INCA, JEOL Ltd., Tokyo, Japan) was used for the study of morphology and determination of chemical composition of fabricated films. The uncertainty of EDS 
measurements for studied films is typically \pm 1 at. $\%$. The surface morphology of the films was studied using atomic force microscope (AFM) Solver Next (NT-MDT Co., Moscow, Russia) in amplitude modulated (AM-AFM) mode with scanned area of $5 \times 5 \mu \mathrm{m}$.

Transmittance and reflectance spectra were measured in UV/Vis/NIR range $(350-2500 \mathrm{~nm})$ employing Lambda 1050 spectrophotometer (Perkin-Elmer Inc., Waltham, MA, USA).

Optical bandgap energy (hereinafter referred to as Tauc gap ） was obtained from energy dependence of $(\alpha E)^{1 / 2}$ (where $\alpha$ is an absorption coefficient) by an extrapolation the linear part of the absorption edge curve found in the high absorption region $\left(\alpha \gtrsim 10^{4} \mathrm{~cm}^{-1}\right)$ [35].

Optical bandgap was also determined from variable angle spectroscopic ellipsometry (VASE, J. A. Woollam Co., Inc., Lincoln, NE, USA) data measured in spectral range $300-2300$ nm with wavelength step of $10 \mathrm{~nm}$, at angles of incidence 50 and $60^{\circ}$. VASE was used to obtain refractive index $(n)$ spectral dependencies and thicknesses of the films too. Imaginary part of dielectric function $\varepsilon_{2}$ was modelled using Cody-Lorentz oscillator model described elsewhere [36]. This model has been recently somewhat preferred ahead of Tauc-Lorentz oscillator model, since it reasonably takes into account the sub-bandgap absorption [37-39]. For a clarity, the values of optical bandgap energies determined by VASE are indicated as .

Local structure of the films was studied using micro-Raman spectroscopy (LabRam HR800, Horiba Jobin-Yvon, NJ, USA) coupled with a $\times 100$ microscope (Olympus, JP) with excitation wavelength of $785 \mathrm{~nm}$. Laser intensity was attenuated using neutral density filters in order to use only few $\mathrm{mW}$ to prevent films against any damage. Raman spectra were reduced by

[ex - $\quad$, where $\hbar$ and $k_{B}$ stands for reduced Planck and Boltzmann constants, respectively [40]. Normalization of the spectra was done by means of their division by maximum intensity values. 
Finally, room-temperature photo-induced effects in fabricated films under the irradiation of $~ 150$ $\mathrm{mW} . \mathrm{cm}^{-2}$ with near bandgap energy laser sources were studied using VASE and micro-Raman spectroscopy. Five different laser wavelengths were used for the irradiation: $532 \mathrm{~nm}(2.33 \mathrm{eV})$, $593 \mathrm{~nm}(2.09 \mathrm{eV}), 635 \mathrm{~nm}(1.95 \mathrm{eV}), 690 \mathrm{~nm}(1.80 \mathrm{eV})$ and $808 \mathrm{~nm}(1.53 \mathrm{eV})$. We note that the samples were always irradiated by only one near bandgap source for which the penetration depth was larger but close to the film thickness. Films were exposed for 180 minutes; the distance between irradiated film and laser source was kept constant $(75 \mathrm{~cm})$. The shift of the fundamental short-wavelength absorption edge was also controlled by direct transmission measurements using EPP 2000 portable spectrophotometer (StellarNet Inc., Tampa, FL, USA) operating in UV-VisNIR region. Photosensitivity experiments were carried out under the pure Ar atmosphere in order to minimize the effect of surface photo-oxidation, especially in case of Ge-rich samples.

\section{Results and discussion}

\section{1. Chemical composition, morphology and topography}

In order to fabricate representative Ge-Sb-Se films by means of chemical composition, morphology, topography and optical properties, the range of thicknesses of $\sim 440-1080 \mathrm{~nm}$ was found to be optimal. This is achieved via adjusting the electrical power applied on individual cathodes as well as setting suitable duration of deposition, i.e. 120 and 150 minutes for single cathode depositions and co-sputtering, respectively. The resulting film thicknesses estimated from VASE data and chemical composition determined via EDS are listed in Table I together with other deposition parameters. 
The chemical composition of sputtered films obtained from single $\left(\mathrm{GeSe}_{2}, \mathrm{Sb}_{2} \mathrm{Se}_{3}\right.$ or $\mathrm{Ge}_{28} \mathrm{Sb}_{12} \mathrm{Se}_{60}$ ) cathode was generally found to be close to the composition of targets, in frame of uncertainty of EDS measurements (Table I).

It is worth to mention that the electrical power of $5 \mathrm{~W}$ on the $\mathrm{GeSe}_{2}$ cathode (sample $\mathrm{Nr}$. 2) does not allow the identification of germanium by EDS, indicating that the content of germanium is below the threshold limit of this technique even for long experiment with deposition time of 200 minutes resulting in the film with thickness of $1110 \mathrm{~nm}$. It can be explained by the fact that deposition rate at $5 \mathrm{~W}$ applied on this single cathode is quite low $(\sim 0.6 \mathrm{~nm} / \mathrm{min})$ compare to the target $\mathrm{Sb}_{2} \mathrm{Se}_{3}$ (C3) $(15 \mathrm{~W}, 6.2 \mathrm{~nm} / \mathrm{min})$ according to the 240 minutes long experiment. Furthermore, the average deposition rate at $10 \mathrm{~W}(15 \mathrm{~W})$ is $\sim 1.9(3.7) \mathrm{nm} / \mathrm{min}, \sim 3.0(6.2) \mathrm{nm} / \mathrm{min}$ and 2.4 (4.8) $\mathrm{nm} / \mathrm{min}$ for $\mathrm{GeSe}_{2}(\mathrm{C} 1), \mathrm{Sb}_{2} \mathrm{Se}_{3}(\mathrm{C} 2)$ and $\mathrm{Ge}_{28} \mathrm{Sb}_{12} \mathrm{Se}_{60}$ (C3) single targets, respectively. Moreover, EDS analysis showed that despite having different deposition rates (in the range of $1.9-3 \mathrm{~nm} / \mathrm{min}$ ), the real chemical composition $\mathrm{Ge}_{12.3} \mathrm{Sb}_{24.8} \mathrm{Se}_{62.9}$ of co-sputtered film deposited from cathodes $\mathrm{C} 1+\mathrm{C} 2$ (sample Nr. 5 in Table I) at 10/10 W is very close to an expected composition of pseudo-binary $\left(\mathrm{GeSe}_{2}\right)_{50}\left(\mathrm{Sb}_{2} \mathrm{Se}_{3}\right)_{50}$ considering deposition rate, density and molecular weight of the two targets, i.e. $\mathrm{Ge}_{12.5} \mathrm{Sb}_{25} \mathrm{Se}_{62.5}$. This is the case also for co-sputtered film from C1+C3 (sample Nr. 11 in Table I) at 10/10 W where the real chemical composition of the co-sputtered film is $\mathrm{Ge}_{30.6} \mathrm{Sb}_{6.7} \mathrm{Se}_{62.7}$ close to expected composition of $(\mathrm{C} 1)_{50}(\mathrm{C} 3)_{50}$, i.e. $\mathrm{Ge}_{30.7} \mathrm{Sb}_{6} \mathrm{Se}_{63.3}$. Finally, film deposited from C2+C3 (sample Nr. 15 in Table I) at 10/10 W contains slightly more antimony at the expense of germanium when compared to $(\mathrm{C} 2)_{50}(\mathrm{C} 3)_{50}$. The real chemical composition found for this film is $\mathrm{Ge}_{11.2} \mathrm{Sb}_{28.4} \mathrm{Se}_{60.4}$ while the expected composition could be $\mathrm{Ge}_{14} \mathrm{Sb}_{26} \mathrm{Se}_{60}$ showing the limitation of predictive approach of co-sputtered film composition without a perfect knowledge of single cathode deposition rate, plasma characteristics, density and molecular weight of targets and films affecting the chemical 
composition of the co-sputtered films. It is worth to mention that the selenium content in these films is well maintained for used RF power and Ar working pressure. Moreover, depositions from cathode combinations mentioned above (i.e. $\mathrm{C} 1+\mathrm{C} 2, \mathrm{C} 1+\mathrm{C} 3$ and $\mathrm{C} 2+\mathrm{C} 3$ ) with the electrical power ratio equal to 1 were also carried out at 15/15 W (not shown in Table I). Resulting compositions of the films after 75 minutes long depositions, in order to match the desired thickness range, were $\mathrm{Ge}_{11.5} \mathrm{Sb}_{26.6} \mathrm{Se}_{61.9}(\mathrm{C} 1+\mathrm{C} 2), \mathrm{Ge}_{29.3} \mathrm{Sb}_{7.8} \mathrm{Se}_{62.9}(\mathrm{C} 1+\mathrm{C} 3)$ and $\mathrm{Ge}_{11.3} \mathrm{Sb}_{29.1} \mathrm{Se}_{59.6}$ $(\mathrm{C} 2+\mathrm{C} 3)$ respectively. Resulting thicknesses were $710(\mathrm{C} 1+\mathrm{C} 2), 620(\mathrm{C} 1+\mathrm{C} 3)$ and $780 \mathrm{~nm}$ $(\mathrm{C} 2+\mathrm{C} 3)$. The difference in the composition comparing $10 / 10 \mathrm{~W}$ and $15 / 15 \mathrm{~W}$ is logical when taking growth rate ratios into account.

SEM images of the surface (Fig. 1 a, b and c) show good smoothness of the fabricated cosputtered films. The good homogeneity of the films without any pores, columnar structures or cracks was confirmed by the cross-section SEM images (Fig. 1 d, e and f).

Generally, good quality of co-sputtered films was also confirmed by AFM measurements performed within silicon substrates (scanned area of $5 \times 5 \mu \mathrm{m}$ ), giving the root mean square roughness $(\mathrm{Sq})$ values typically $\sim 0.4 \pm 0.2 \mathrm{~nm}$. Nevertheless, some differences in topography were found when particular targets were used. As shown on Fig. $2 \mathrm{~d}$ and e, when $\mathrm{Ge}_{28} \mathrm{Sb}_{12} \mathrm{Se}_{60}(\mathrm{C} 3)$ is involved, the films tend to have grainier surface. On the other hand, single cathode sputtered films of $\mathrm{Sb}_{2} \mathrm{Se}_{3}$ and $\mathrm{GeSe}_{2}$ have very smooth surface, confirmed by low Sq values (Fig. 2 a and c).

It should be noted that the Sq values are lower than the data published by Balan et al. for sputtered $\mathrm{Ge}_{28} \mathrm{Sb}_{12} \mathrm{Se}_{60}$ films (thickness of $200 \mathrm{~nm}$ ) measured on area of $1 \times 1 \mu \mathrm{m}$ giving the Sq value of $1.1 \mathrm{~nm}[41]$. Moreover, data presented in Ref. 41 indicate columnar structure of fabricated films. Contrary, our data confirm a very good quality of co-sputtered Ge-Sb-Se films fabricated in this study. 


\section{2. Optical characteristics}

The summary of the optical characteristics of selected co-sputtered films is shown in Table II. For single cathode depositions, optical bandgap of sputtered $\mathrm{Sb}_{2} \mathrm{Se}_{3}$ films is $1.35 \pm 0.01 \mathrm{eV}$ as determined by VASE. of these films was found to be $1.39 \pm 0.02 \mathrm{eV}$. These values are in a good agreement with the one published by Chen et al. for evaporated $\mathrm{Sb}_{2} \mathrm{Se}_{3}$ films with the value of $1.39 \pm 0.2 \mathrm{eV}$ as determined by ellipsometry [42]. Furthermore, value of $2.08 \pm 0.02 \mathrm{eV}$ and $E_{g}^{T}$ of $2.11 \pm 0.02 \mathrm{eV}$ for sputtered $\mathrm{GeSe}_{2}$ films is close to the data published by various authors. For evaporated films, the value of optical bandgap of $2.06 \mathrm{eV}$ as determined by Tauc extrapolation was reported by Tichý et al. [43]. For sputtered $\mathrm{GeSe}_{2}$ film, the optical bandgap energy was found to be $2.04 \mathrm{eV}$ using the same approach as published by Chen et al.[31]. Finally, $E_{g}^{C}$ and for films sputtered using $\mathrm{Ge}_{28} \mathrm{Sb}_{12} \mathrm{Se}_{60}$ target were found to be $1.66 \pm 0.02 \mathrm{eV}$ and $1.74 \pm 0.02 \mathrm{eV}$ respectively. The values are in very good agreement with data reported by Balan $e t$ al. for sputtered films with $\sim 1.65 \mathrm{eV}$ (Tauc relation) [41].

Despite the fact that the band structure of ternary glasses is not precisely known, the general trends connected with the normal bonding structure of Ge-Sb-Se system can be predicted. Proposed assumption is based on the following. First, electronic structure of both amorphous and crystalline GeSe2 was well described through the density functional theory (DFT) of the valence band (VB) and conduction band (CB) density of states (DOS) [44]. The VB top is comprising from Se $4 p$ lone-pair ( $l p$ ) states, while CB bottom is described as coming from Ge $4 s$-Se $4 p$ antibonding states[44]. Moreover, according Carey et al., in $\mathrm{Sb}_{2} \mathrm{Se}_{3}$ the VB is comprised of $\mathrm{Sb} 5 s / p$ with a contribution from Se $4 p$ states, based on the DFT calculation [45]. According XPS data published by Sati et al. for bulk $\mathrm{Ge}_{40-\mathrm{x}} \mathrm{Sb}_{\mathrm{x}} \mathrm{Se}_{60}(\mathrm{x}=8,20)$ glasses [46], the peaks in the spectra 
ascribed to $\mathrm{Se} l p$ electron states and $\mathrm{Sb} 5 p$ bonding electrons in $\mathrm{Sb}-\mathrm{Sb}$ bonds are found at the very top of the valence band. Another contributions found at the valence band maxima (VBM) are coming from Ge $4 p$ states participating in $\mathrm{Ge}-\mathrm{Ge}$ bonding and $\mathrm{Se} 4 p$ states [46]. Similar behavior was found in the XPS valence band spectra in bulk Ge-Sb-S glasses (Ge $4 p, \mathrm{~S} 3 p$ and $\mathrm{S}$ lp at the VBM) [47]. Slight shift in the binding energy might be seen in the XPS valence band spectra when one compares $\mathrm{Ge}_{32} \mathrm{Sb}_{8} \mathrm{Se}_{60}$ and $\mathrm{Ge}_{20} \mathrm{Sb}_{20} \mathrm{Se}_{60}$ glasses [46]. Thus it seems reasonable that the $\mathrm{Sb} 5 p$ bonding electrons contributing to $\mathrm{VBM}$ are responsible for the reduction of bandgap energy in Ge-Sb-Se system when increasing antimony content.

It should be noted that the lower values of when compared to (Table II) are reasonably explained when one compares the methodology of determination of optical bandgap values by these two techniques.

As depicted in Fig. 3 and Fig. 4 and listed in Table II, the properties of co-sputtered films in the Ge-Sb-Se ternary diagram can be gradually tailored in terms of bandgap $(E \quad)$ and refractive index values. Thanks to co-sputtering deposition method, wide range of bandgap energy of the Ge-Sb-Se films is obtained by a simple variation of the co-sputtering deposition parameters between the three extreme values represented by the three targets: $1.35 \mathrm{eV}$ for $\mathrm{Sb}_{2} \mathrm{Se}_{3}, 1.66$ $\mathrm{eV}$ for $\mathrm{Ge}_{28} \mathrm{Sb}_{12} \mathrm{Se}_{60}$ and finally the largest bandgap of $2.08 \mathrm{eV}$ for $\mathrm{GeSe}_{2}$. Most likely, the tunability of the refractive index of co-sputtered thin films is more noticeable since changeable in broad range from 3.33 to 2.36 at $1550 \mathrm{~nm}$. 


\section{3. Local structure by Raman scattering spectroscopy}

Local structure of co-sputtered films was studied via analysis of Raman scattering spectroscopy (Fig. 5). For Ge-rich films, typical Raman bands peaking at $\sim 198$ and $216 \mathrm{~cm}^{-1}$ dominate the spectra. They are attributed to the symmetric stretching vibrations of heteropolar Ge-Se bonds in the corner-sharing $\left(A_{1}\right)$ and edge-sharing (or also companion mode $\quad$ ) [ $\left.\mathrm{GeSe}_{4 / 2}\right]$ tetrahedra [8, 16, 18, 48, 49]. Furthermore, Raman bands corresponding to the stretching modes of homopolar $\mathrm{Ge}-\mathrm{Ge}$ bonds in $\left[\mathrm{Ge}_{2} \mathrm{Se}_{6 / 2}\right]$ and $\left[\mathrm{Ge}-\mathrm{Ge}_{\mathrm{m}} \mathrm{Se}_{4-\mathrm{m}}\right](\mathrm{m}=1,2,3,4)$ entities are found in studied films at $\sim 175 \mathrm{~cm}^{-1}$ accompanied with a small contribution at $\sim 270 \mathrm{~cm}^{-1}$ [30]. It is worth to mention, that the Raman band assigned to $\mathrm{Ge}-\mathrm{Ge}$ vibrations $\left(\sim 175 \mathrm{~cm}^{-1}\right)$ becomes more significant when the $\mathrm{Ge}_{28} \mathrm{Sb}_{12} \mathrm{Se}_{60}$ target is involved. The presence of $\mathrm{Ge}-\mathrm{Ge}$ homopolar bonds, which is likely due to the deficit of selenium in studied films, is plausibly more significant when using $\mathrm{Ge}_{28} \mathrm{Sb}_{12} \mathrm{Se}_{60}$ (C3) target presenting intrinsically a deficit of selenium. This is not the case for $\mathrm{GeSe}_{2}(\mathrm{C} 1)$ and $\mathrm{Sb}_{2} \mathrm{Se}_{3}(\mathrm{C} 2)$ respecting the stoichiometry of the main $\left[\mathrm{GeSe}_{4 / 2}\right]$ and $\left[\mathrm{SbSe}_{3 / 2}\right]$ entities forming the glassy network. For the films where the higher power (13 and $15 \mathrm{~W}$ ) was applied onto $\mathrm{GeSe}_{2}$ (C1) cathode, the content of Ge-Ge homopolar bonds was not found to be comparatively significant as for $\mathrm{Ge}_{28} \mathrm{Sb}_{12} \mathrm{Se}_{60}(\mathrm{C} 3)$. Even if $\mathrm{GeSe}_{2}$ films could be deficient in selenium, their higher selenium content, in relative comparison to $\mathrm{C} 3$ target, probably causes the creation of more favorable hetero-polar bonds during the deposition process. Symmetric stretching vibrations of corner-sharing $\left(A_{1}\right)$ and edge-sharing $\left(A_{1}^{C}\right)$ [GeSe $\left.\mathrm{Ge}_{4 / 2}\right]$ tetrahedra in Ge-rich films gradually evolve to $\mathrm{Sb}$ - $\mathrm{Se}$ stretching vibration modes in $\left[\mathrm{SbSe}_{3 / 2}\right]$ pyramidal units when decreasing Ge concentration, resulting in the high intensity, broad Raman band peaking at $\sim 190 \mathrm{~cm}^{-1}$ in stoichiometric $\mathrm{Sb}_{2} \mathrm{Se}_{3}$ films [18, 50]. 
Apart from weak Raman band at $\sim 270 \mathrm{~cm}^{-1}$, several other contributions can be found in $\sim 250-$ $330 \mathrm{~cm}^{-1}$ region. First, $\mathrm{Se}-$ Se stretching mode at the outrigger is located at $\sim 235 \mathrm{~cm}^{-1}$. Another contribution is considered to originate from $\mathrm{Se}-\mathrm{Se}$ bonds' vibrations at $\sim 265 \mathrm{~cm}^{-1}$ coming from $\left[\mathrm{GeSe}_{4 / 2}\right]$ tetrahedra where at least one of the selenium at the tetrahedron corner is linked to another selenium, forming $\mathrm{Se}-\mathrm{Se}$ dimers or short $\mathrm{Se}_{\mathrm{n}}$ chains $[30,50]$. Finally, $\mathrm{F}_{2}$ asymmetric vibration modes of [GeSe $4 / 2$ ] tetrahedra at $\sim 305 \mathrm{~cm}^{-1}$ contribution have to be mentioned [51].

Weak band usually ascribed to $\mathrm{Se}-\mathrm{Se}$ bending mode vibrations was found at $\sim 136 \mathrm{~cm}^{-1}$ [10]. Low intensity Raman band found in stoichiometric $\mathrm{Sb}_{2} \mathrm{Se}_{3}$ films at $\sim 249 \mathrm{~cm}^{-1}$, assigned to $\mathrm{Se}-\mathrm{Se}$ bond stretching vibrations in short selenium chains, shifts towards higher wavenumbers with increasing Ge concentration [8]. For Sb rich samples, the low intensity Raman band with maximum at $\sim 159 \mathrm{~cm}^{-1}$ can be connected with $\mathrm{Sb}-\mathrm{Sb}$ homopolar bonds' vibrations in the $\mathrm{Se}_{2} \mathrm{Sb}$ $\mathrm{SbSe}_{2}$ units [51].

\section{4. Photo-induced effects in co-sputtered as-deposited Ge-Sb-Se films by near- bandgap irradiation}

Photo-induced changes of optical bandgap energy and refractive index as determined by VASE for all the as-deposited co-sputtered films are summarized in Table II. For reader's convenience, these changes are also depicted in Fig. 6.

Data presented in Table II and Fig. 6 were calculated as differences between or $n$ values after 180 minutes of irradiation under pure Ar atmosphere and before irradiation. We remind here that the irradiation wavelength was chosen with respect to the bandgap energy of the individual cosputtered films and in accordance with the penetration depth of the light used for the irradiation. Generally, photo-induced blue shift (PB) of the bandgap energy was observed for the Ge-rich 
films. In detail, the increase by $0.1 \mathrm{eV}$ was observed for $\mathrm{GeSe}_{2}$ film after the irradiation by 532 nm laser source. Among all of the compositions, this was found to be the most significant shift of the optical bandgap. Observation of photobleaching of as-deposited $\mathrm{GeSe}_{2}$ films under vacuum prepared by conventional thermal evaporation technique was previously reported by Tichy et al. [43]. The PB tends to decrease with increasing antimony content up to $\mathrm{Sb}_{2} \mathrm{Se}_{3}$, which was found to be photo-stable by means of zero change of . These results support the data previously published by Olivier et al. for pulsed laser deposited Ge-Sb-Se films [18]. Furthermore, only small PB was observed for the $\mathrm{Ge}_{28} \mathrm{Sb}_{12} \mathrm{Se}_{60}$ films, with the bandgap energy increment of $0.03 \mathrm{eV}$ when irradiated by $635 \mathrm{~nm}$ laser source. Moreover, slight photo-induced increase in refractive index values of Sb-rich films has been observed. Specifically, for samples Nr. 2, 3, 5 and 16, the changes in refractive index are in the range 0.04-0.05.

Direct transmission measurements using portable spectrophotometer were carried out in order to quickly control the shift of the absorption edge before and after irradiation. It should be noted that the noise of the transmission spectra on the Fig. 7 is caused because of the low value of integration time on spectrophotometer detector $(500 \mathrm{~ms})$. Transmission spectra for $\mathrm{C} 1\left(\mathrm{GeSe}_{2}\right) / \mathrm{C} 2\left(\mathrm{Sb}_{2} \mathrm{Se}_{3}\right) \quad 10 / 10 \quad \mathrm{~W} \quad\left(\mathrm{Ge}_{12.3} \mathrm{Sb}_{24.8} \mathrm{Se}_{62.9}-\right.$ Fig. 7 top right panel $)$ and $\mathrm{C} 2\left(\mathrm{Sb}_{2} \mathrm{Se}_{3}\right) / \mathrm{C} 3\left(\mathrm{Ge}_{28} \mathrm{Sb}_{12} \mathrm{Se}_{60}\right)$ 10/10 $\mathrm{W}\left(\mathrm{Ge}_{11.2} \mathrm{Sb}_{28.4} \mathrm{Se}_{60.4}\right.$ - Fig. 7 bottom right panel) films confirm the results obtained from VASE, where the change in the bandgap does not exceed the deviation of VASE measurements (irradiated by 690 and $730 \mathrm{~nm}$ laser source). Moreover, also the film deposited at $\mathrm{C} 1 / \mathrm{C} 211 / 9 \mathrm{~W}\left(\mathrm{Ge}_{16.4} \mathrm{Sb}_{19.4} \mathrm{Se}_{64.2}\right.$ - sample Nr. 6) was found to be photostable by means of change in the bandgap not exceeding the deviation of VASE measurements $(\Delta E=0.01)$ when irradiated by $635 \mathrm{~nm}$ laser source. On the other hand, next two examples of films' transmission spectra, presented in top left (sample Nr. 10) and bottom left (sample Nr. 11) 
panels of Fig. 7, qualitatively confirm PB revealed by VASE data $(\Delta \quad$ of 0.09 and $0.06 \mathrm{eV}$ respectively).

Raman scattering spectra analysis of co-sputtered films before and after exposure did not confirm that optical bandgap energy shift is strictly due to homo-to-heteropolar bond conversion. This observation is evidenced by a comparison of Raman spectra of two selected Ge-rich films presenting important photo-induced changes before and after irradiation as shown in Fig. 8.

\section{Conclusions}

Thin films of amorphous Ge-Sb-Se were fabricated by rf magnetron sputtering technique employing multiple cathodes (co-sputtering). Films have been found to be of good optical quality with surface roughness typically around $\sim 0.4 \pm 0.2 \mathrm{~nm}$, no columnar structures and appropriate thickness uniformity. Bandgap range $1.35-2.08 \mathrm{eV}$ with corresponding refractive index values ranging from 3.33 to 2.36 can be reliably covered when three targets with following composition are used: $\mathrm{GeSe}_{2}, \mathrm{Sb}_{2} \mathrm{Se}_{3}, \mathrm{Ge}_{28} \mathrm{Sb}_{12} \mathrm{Se}_{60}$. The study of the photosensitivity of co-sputtered films under Ar atmosphere showed that the germanium is responsible for PB effect when irradiated by near-bandgap light. The PB effect tends to decrease with increasing antimony content. Good optical quality in combination with low photosensitivity makes amorphous selenide films from Ge-Sb-Se system with Se content in the range of 60-70 at. \% fabricated by co-sputtering suitable for various applications in the field of photonics where the light propagation within the material without any significant changes caused by light are required. 


\section{Acknowledgements}

Financial support from CNRS and French National Grant Agency (ANR 15-CE04-0001-01) and the Czech Science Foundation (Project No. 16-17921S) are greatly acknowledged. This work was also supported by the grants LM2015082 and CZ.1.05/4.1.00/11.0251 from the Ministry of Education, Youth and Sports of the Czech Republic. T. H. would like also express gratitude to the French Embassy for $\mathrm{PhD}$ funds allowing student mobility.

\section{References}

1. Eggleton B.J., Luther-Davies B., Richardson K. Chalcogenide photonics. Nat. Photon. 2011;5:141-148.

2. Tanaka K., Photo-induced phenomena in chalcogenide glasses. In: Adam J.L., Zhang X., Chalcogenide Glasses: Preparation, Properties and Applications, Elsevier Science, 2014, 139-168.

3. Adam J.-L., Calvez L., Trolès J., et al. Chalcogenide Glasses for Infrared Photonics. Int. J. Appl. Glass Sci. 2015;6:287-294.

4. Ta'eed V.G., Baker N.J., Fu L., et al. Ultrafast all-optical chalcogenide glass photonic circuits. Opt. Express. 2007; 15:9205-9221.

5. S Sútorová K., Prokeš L., Nazabal V., et al. Laser Desorption Ionization Time-of-Flight Mass Spectrometry of Glasses and Amorphous Films from Ge-As-Se System. J. Am. Ceram. Soc. 2016;99:3594-3599.

6. $\quad$ Němec P., Olivier M., Baudet E., et al. Optical properties of (GeSe2)100-x(Sb2Se3)x glasses in near- and middle-infrared spectral regions. Mater. Res. Bull. 2014;51:176-179.

7. Olivier M., Tchahame J.C., Němec P., et al. Structure, nonlinear properties, and photosensitivity of $(\mathrm{GeSe} 2) 100-\mathrm{x}(\mathrm{Sb} 2 \mathrm{Se} 3) \mathrm{x}$ glasses. Opt. Mater. Express. 2014;4:525-540.

$8 . \quad$ Wei W.-H., Wang R.-P., Shen X., et al. Correlation between Structural and Physical Properties in Ge-Sb-Se Glasses. J. Phys. Chem. C. 2013;117:16571-16576.

9. Chen L.Y., Chen F.F., Dai S.X., et al. Third-order nonlinearity in Ge-Sb-Se glasses at midinfrared wavelengths. Mater. Res. Bull. 2015;70:204-208.

10. Baudet E., Cardinaud C., Girard A., et al. Structural analysis of RF sputtered Ge-Sb-Se thin films by Raman and X-ray photoelectron spectroscopies. J. Non-Cryst. Solids. 2016;444:64-72.

11. Verger F., Nazabal V., Colas F., et al. RF sputtered amorphous chalcogenide thin films for surface enhanced infrared absorption spectroscopy. Opt. Mater. Express. 2013;3:2112-2131.

12. Baudet E., Sergent M., Němec P., et al. Experimental design approach for deposition optimization of RF sputtered chalcogenide thin films devoted to environmental optical sensors. Sci. Rep. 2017;7:3500.

13. Aly K.A., Abousehly A.M., Osman M.A., et al. Structure, optical and electrical properties of Ge30Sb10Se60 thin films. Phys. B: Condens. Matter. 2008;403:1848-1853.

14. Martín-Palma R.J., Ryan J.V., Pantano C.G. Surface microstructure of GeSbSe chalcogenide thin films grown at oblique angle. J. Appl. Phys. 2007;101:083513. 
15. Ganjoo A., Jain H., Khalid S., et al. Structural modification of Ge-Se amorphous films with the addition of Sb. Phil. Mag. Lett. 2005;85:503-512.

16. Chen Y., Shen X., Wang R., et al. Optical and structural properties of Ge-Sb-Se thin films fabricated by sputtering and thermal evaporation. J. Alloys Comp. 2013;548:155-160.

17. Lin L., Wang G., Shen X., et al. Photo-induced structural changes in Ge-Sb-Se films. Infrared Phys. \& Technol. 2017;81:59-63.

18. Olivier M., Němec P., Boudebs G., et al. Photosensitivity of pulsed laser deposited Ge-Sb-Se thin films. Opt. Mater. Express. 2015;5:781-793.

19. Fritzsche H. The origin of reversible and irreversible photostructural changes in chalcogenide glasses. Phil. Mag. B. 1993;68:561-572.

20. Fritzsche H. Photo-induced fluidity of chalcogenide glasses. Solid State Commun. 1996;99:153-

155.

21. De Neufville J.P., Moss S.C., Ovshinsky S.R. Photostructural transformations in amorphous As2Se3 and As2S3 films. J. Non-Cryst. Solids. 1974;13:191-223.

22. Tanaka K., Kasanuki Y., Odajima A. Physical properties and photoinduced changes of amorphous Ge-S films. Thin Solid Films. 1984;117:251-260.

23. Tanaka K., Shimakawa K., Light-Induced phenomena, Amorphous chalcogenide semiconductors and related materials, New York Springer Science+Business Media, 2011,141-193

24. Shimakawa K., Kolobov A., Elliott S.R. Photoinduced effects and metastability in amorphous semiconductors and insulators. Advances in Physics. 1995;44:475-588.

25. Yan Q., Jain H., Ren J., et al. Effect of Photo-Oxidation on Photobleaching of GeSe2 and Ge2Se3 Films. J. Phys. Chem. C. 2011;115:21390-21395.

26. Street R.A., Nemanich R.J., Connell G.A.N. Thermally induced effects in evaporated chalcogenide films. II. Optical absorption. Phys. Rev. B. 1978;18:6915-6919.

27. Tichý L., Tř́ska A., Tichá H., et al. On the nature of bleaching of amorphous Ge30S70 films.

Phil. Mag. B. 1986;54:219-230.

28. Němec P., Zhang S., Nazabal V., et al. Photo-stability of pulsed laser deposited GexAsySe100-x-y amorphous thin films. Opt. Express. 2010;18:22944-22957.

29. Yang G., Jain H., Ganjoo A., et al. A photo-stable chalcogenide glass. Opt. Express. 2008;16:10565-10571.

30. Nazabal V., Charpentier F., Adam J.-L., et al. Sputtering and Pulsed Laser Deposition for Nearand Mid-Infrared Applications: A Comparative Study of Ge25Sb10S65 and Ge25Sb10Se65 Amorphous Thin Films. Int. J. Appl. Ceram. Technol. 2011;8:990-1000.

31. Chen F., Zhang Z., Wang Y., et al. Optical properties of amorphous In-doped GeSe2 films for alloptical applications. Infrared Phys. \& Technol. 2015;69:32-35.

32. Cho J.-Y., Kim D., Park Y.-J., et al. The phase-change kinetics of amorphous Ge2Sb2Te5 and device characteristics investigated by thin-film mechanics. Acta Mater. 2015;94:143-151.

33. Park T.-J., Choi S.-Y., Kang M.-J. Phase transition characteristics of Bi/Sn doped Ge2Sb2Te5thin film for PRAM application. Thin Solid Films. 2007;515:5049-5053.

34. Wang H., Wang G., Shi D., et al. Compositional dependence of crystallization and structural stability in Ge-Sb-Se chalcogenide films. J. Non-Cryst. Solids. 2016;453:108-112.

35. Tauc J., Optical Properties of Amorphous Semiconductors. In: Tauc J., Amorphous and liquid semiconductors, London, New York, Plenum, 1974, 159-220.

36. Němec P., Moreac A., Nazabal V., et al. Ge-Sb-Te thin films deposited by pulsed laser: An ellipsometry and Raman scattering spectroscopy study. J. Appl. Phys. 2009;106:103509.

37. Ferlauto A.S., Ferreira G.M., Pearce J.M., et al. Analytical model for the optical functions of amorphous semiconductors from the near-infrared to ultraviolet: Applications in thin film photovoltaics. $J$. Appl. Phys. 2002;92:2424-2436.

38. Fujiwara H., Data analysis examples. In: Fujiwara H., Spectroscopic ellipsometry: principles and applications, Chichester, England; Hoboken, NJ John Wiley \& Sons, 2007, 249-310. 
39. Němec P., Nazabal V., Frumar M. Photoinduced phenomena in amorphous As4Se3 pulsed laser deposited thin films studied by spectroscopic ellipsometry. J. Appl. Phys. 2009;106:023509.

40. Shuker R., Gammon R.W. Raman-Scattering Selection-Rule Breaking and the Density of States in Amorphous Materials. Phys. Rev. Lett. 1970;25:222-225.

41. Balan V., Vigreux C., Pradel A. Chalcogenide thin films deposited by radio-frequency sputtering. J. Optoelectron. Adv. Mater. 2004;6:875-882.

42. Chen C., Li W., Zhou Y., et al. Optical properties of amorphous and polycrystalline Sb2Se3 thin films prepared by thermal evaporation. Appl. Phys. Lett. 2015;107:043905.

43. Tichý L., Sleeckx E., Nagels P., et al. The influence of temperature on the optical absorption edge shift induced by band-gap illumination in thin amorphous GeSe2 films. Phil. Mag. B. 1996;73:213-221.

44. Hachiya K. Density functional electronic structures calculations of GeSe2. J.Non-Cryst. Solids. 2001;291:160-166.

45. Carey J.J., Allen J.P., Scanlon D.O., et al. The electronic structure of the antimony chalcogenide series: Prospects for optoelectronic applications. J. Solid State Chem. 2014;213:116-125.

46. Sati D.C., Kovalskiy A., Golovchak R., et al. Structure of SbxGe40-xSe60 glasses around 2.67 average coordination number. J. Non-Cryst. Solids. 2012;358:163-167.

47. Kovalskiy A., Jain H., Miller A.C., et al. A Study of Reversible $\gamma$-Induced Structural Transformations in Vitreous Ge23.5Sb11.8S64.7 by High-Resolution X-ray Photoelectron Spectroscopy. J. Phys. Chem. B. 2006;110:22930-22934.

48. Sugai S. Stochastic random network model in Ge and Si chalcogenide glasses. Phys. Rev. B. 1987;35:1345-1361.

49. Wang Y., Matsuda O., Inoue K., et al. A Raman scattering investigation of the structure of glassy and liquid GexSe1-x. J. Non-Cryst. Solids. 1998;232-234:702-707.

50. Kostadinova O., Yannopoulos S.N. Raman spectroscopic study of SbxSe100-x phase-separated bulk glasses. J. Non-Cryst. Solids. 2009;355:2040-2044.

51. Nazabal V., Němec P., Jurdyc A.M., et al. Optical waveguide based on amorphous Er3+-doped Ga-Ge-Sb-S(Se) pulsed laser deposited thin films. Thin Solid Films. 2010;518:4941-4947.

\section{Figure captions}

Fig. 1. SEM images of the surface (a-C1/C2 10/10 W, b-C1/C3 10/10 W, c - C2/C3 10/10 W) and the cross-section of co-sputtered films (d - C1/C2 10/10 W, e - C1/C3 10/10 W, f - C2/C3 $10 / 10 \mathrm{~W})$.

Fig. 2. AFM images of (co-)sputtered films with indicated root mean square roughness (Sq) values: a-C2 $10 \mathrm{~W}, \mathrm{~b}-\mathrm{C} 2 / \mathrm{C} 1$ 10/10 W, c-C1 $10 \mathrm{~W}, \mathrm{~d}-\mathrm{C} 1 / \mathrm{C} 310 / 10 \mathrm{~W}, \mathrm{e}-\mathrm{C} 2 / \mathrm{C} 310 / 10 \mathrm{~W}$, f - C3 $10 \mathrm{~W}$. 
Fig. 3. Fundamental short-wavelength absorption edge of co-sputtered Ge-Sb-Se films.

Fig. 4. Ge-Sb-Se ternary diagram cut-outs with indicated values of (a) and $n$ (b) of cosputtered films.

Fig. 5. a) Normalized reduced intensity of Raman spectra of co-sputtered Ge-Sb-Se films. b) Gaussian peaks decomposition of Raman spectra of $\mathrm{GeSe}_{2}$ (top panel) and $\mathrm{Ge}_{28} \mathrm{Sb}_{12} \mathrm{Se}_{60}$ (bottom panel) sputtered films deposited at $10 \mathrm{~W}$.

Fig. 6. Ge-Sb-Se ternary diagram cut-outs with indicated values of

$E_{g}^{C} \quad$ (a) and $\Delta n=n$ (irradiated $)-n($ as - deposited $)($ b) of as-deposited cosputtered films.

Fig. 7. Transmission spectra of selected films before and after irradiation by near-bandgap light with indicated composition; C1/C3 15/5 W irradiated by $593 \mathrm{~nm}$ laser source (top left panel), C1/C2 10/10 W irradiated by $690 \mathrm{~nm}$ laser source (top right panel), C1/C3 10/10 W irradiated by $593 \mathrm{~nm}$ laser source (bottom left panel), C2/C3 10/10 W irradiated by $730 \mathrm{~nm}$ laser source (bottom right panel).

Fig. 8. Comparison of reduced Raman spectra of samples Nr. 9 (15 W GeSe 2$)$ and $11(10 \mathrm{~W} / 10$ $\mathrm{W} \mathrm{GeSe}{ }_{2} / \mathrm{Ge}_{28} \mathrm{Sb}_{12} \mathrm{Se}_{60}$ ) before and after irradiation. 


\section{Tables}

Table I. The summary of deposition parameters of selected co-sputtered Ge-Sb-Se thin films deposited at Ar working pressure $5 \times 10^{-3}$ mbar with their thicknesses determined from VASE $( \pm 2$ $\mathrm{nm})$, deposition rate and chemical compositions ( \pm 1 at. \%) evaluated by EDS.

\begin{tabular}{|c|c|c|c|c|c|c|c|}
\hline \multirow{2}{*}{ Nr. } & \multicolumn{3}{|c|}{$\begin{array}{l}\text { Power } \\
\text { (W) }\end{array}$} & \multirow[t]{2}{*}{$\begin{array}{l}\text { Film thickness } \\
\qquad(\mathrm{nm})\end{array}$} & \multirow[t]{2}{*}{$\begin{array}{l}\text { Duration } \\
\text { (min) }\end{array}$} & \multirow[t]{2}{*}{$\begin{array}{l}\text { Deposition } \\
\text { rate }(\mathrm{nm} / \mathrm{min})\end{array}$} & \multirow[t]{2}{*}{$\begin{array}{l}\text { Composition } \\
\text { (at. \%) }\end{array}$} \\
\hline & $\mathrm{GeSe}_{2}$ & $\mathrm{Sb}_{2} \mathrm{Se}_{3}$ & $\mathrm{Ge}_{28} \mathrm{Sb}_{12} \mathrm{Se}_{60}$ & & & & \\
\hline 1 & - & 15 & - & 740 & 120 & 6.2 & $\mathrm{Sb}_{39.4} \mathrm{Se}_{60.6}$ \\
\hline 2 & 5 & 15 & - & 950 & 150 & 6.3 & $\mathrm{Sb}_{39.9} \mathrm{Se}_{60.1}$ \\
\hline 3 & 7 & 13 & - & 890 & 150 & 5.9 & $\mathrm{Ge}_{5.0} \mathrm{Sb}_{33.4} \mathrm{Se}_{61.6}$ \\
\hline 4 & 9 & 11 & - & 810 & 150 & 5.4 & $\mathrm{Ge}_{9.5} \mathrm{Sb}_{28.7} \mathrm{Se}_{61.8}$ \\
\hline 5 & 10 & 10 & - & 830 & 150 & 5.5 & $\mathrm{Ge}_{12.3} \mathrm{Sb}_{24.8} \mathrm{Se}_{62.9}$ \\
\hline 6 & 11 & 9 & - & 750 & 150 & 5.0 & $\mathrm{Ge}_{16.4} \mathrm{Sb}_{19.4} \mathrm{Se}_{64.2}$ \\
\hline 7 & 13 & 7 & - & 650 & 150 & 4.3 & $\mathrm{Ge}_{23.4} \mathrm{Sb}_{11.5} \mathrm{Se}_{65.1}$ \\
\hline 8 & 15 & 5 & - & 670 & 150 & 4.5 & $\mathrm{Ge}_{27.7} \mathrm{Sb}_{5.9} \mathrm{Se}_{66.4}$ \\
\hline 9 & 15 & - & - & 440 & 120 & 3.7 & $\mathrm{Ge}_{32.1} \mathrm{Se}_{67.9}$ \\
\hline 10 & 15 & - & 5 & 710 & 150 & 4.7 & $\mathrm{Ge}_{32.5} \mathrm{Sb}_{1.2} \mathrm{Se}_{66.3}$ \\
\hline 11 & 10 & - & 10 & 700 & 150 & 4.7 & $\mathrm{Ge}_{30.6} \mathrm{Sb}_{6.7} \mathrm{Se}_{62.7}$ \\
\hline 12 & 5 & - & 15 & 720 & 150 & 4.8 & $\mathrm{Ge}_{27.3} \mathrm{Sb}_{12.3} \mathrm{Se}_{60.4}$ \\
\hline 13 & - & - & 15 & 570 & 120 & 4.8 & $\mathrm{Ge}_{27.7} \mathrm{Sb}_{12.3} \mathrm{Se}_{60.0}$ \\
\hline 14 & - & 5 & 15 & 840 & 150 & 5.6 & $\mathrm{Ge}_{23.3} \mathrm{Sb}_{16.0} \mathrm{Se}_{60.7}$ \\
\hline 15 & - & 10 & 10 & 880 & 150 & 5.9 & $\mathrm{Ge}_{11.2} \mathrm{Sb}_{28.4} \mathrm{Se}_{60.4}$ \\
\hline 16 & - & 15 & 5 & 1080 & 150 & 7.2 & $\mathrm{Ge}_{3.0} \mathrm{Sb}_{36.3} \mathrm{Se}_{60.7}$ \\
\hline
\end{tabular}


Table II. The summary of optical characteristics and photosensitivity of selected co-sputtered Ge-Sb-Se thin films: bandgap energies estimated from Tauc's plots $\left(E_{g}^{T}, \pm 0.02 \mathrm{eV}\right)$, bandgap energies determined by VASE $(E, \pm 0.01 \mathrm{eV})$ and refractive indices $( \pm 0.01)$ determined by VASE at $1.55 \mu \mathrm{m}$, photo-induced change of optical bandgap ((
$E_{g}^{C}$
)$)$ and refractive index $(\Delta n=n$ (irradiated $)-n($ as - deposited $))$. For

reader's convenience, chemical composition of the films (by EDS) is shown too.

\begin{tabular}{ccccccc}
\hline Nr. & $\begin{array}{c}\text { Composition } \\
(\text { at. \%) }\end{array}$ & $(\mathrm{eV})$ & $(\mathrm{eV})$ & $n$ & $(\mathrm{eV})$ & $\Delta n$ \\
\hline 1 & $\mathrm{Sb}_{39.4} \mathrm{Se}_{60.6}$ & 1.39 & 1.35 & 3.33 & 0.00 & 0.02 \\
\hline 2 & $\mathrm{Sb}_{39.9} \mathrm{Se}_{60.1}$ & 1.39 & 1.35 & 3.31 & 0.00 & 0.04 \\
\hline 3 & $\mathrm{Ge}_{5.0} \mathrm{Sb}_{33.4} \mathrm{Se}_{61.6}$ & 1.52 & 1.46 & 3.07 & -0.01 & 0.04 \\
\hline 4 & $\mathrm{Ge}_{9.5} \mathrm{Sb}_{28.7} \mathrm{Se}_{61.8}$ & 1.64 & 1.53 & 2.93 & 0.01 & 0.00 \\
\hline 5 & $\mathrm{Ge}_{12.3} \mathrm{Sb}_{24.8} \mathrm{Se}_{62.9}$ & 1.68 & 1.61 & 2.80 & 0.01 & 0.04 \\
\hline 6 & $\mathrm{Ge}_{16.4} \mathrm{Sb}_{19.4} \mathrm{Se}_{64.2}$ & 1.78 & 1.68 & 2.70 & 0.01 & 0.02 \\
\hline 7 & $\mathrm{Ge}_{23.4} \mathrm{Sb}_{11.5} \mathrm{Se}_{65.1}$ & 1.95 & 1.83 & 2.53 & 0.04 & 0.01 \\
\hline 8 & $\mathrm{Ge}_{27.7} \mathrm{Sb}_{5.9} \mathrm{Se}_{66.4}$ & 2.03 & 1.94 & 2.45 & 0.04 & -0.02 \\
\hline 9 & $\mathrm{Ge}_{32.1} \mathrm{Se}_{67.9}$ & 2.11 & 2.08 & 2.36 & 0.1 & -0.01 \\
\hline 10 & $\mathrm{Ge}_{32.5} \mathrm{Sb}_{1.2} \mathrm{Se}_{66.3}$ & 2.08 & 2.03 & 2.37 & 0.09 & 0.00 \\
\hline 11 & $\mathrm{Ge}_{30.6} \mathrm{Sb}_{6.7} \mathrm{Se}_{62.7}$ & 1.94 & 1.91 & 2.48 & 0.06 & -0.01 \\
\hline 12 & $\mathrm{Ge}_{27.3} \mathrm{Sb}_{12.3} \mathrm{Se}_{60.4}$ & 1.75 & 1.66 & 2.64 & 0.04 & 0.03 \\
\hline 13 & $\mathrm{Ge}_{27.7} \mathrm{Sb}_{12.3} \mathrm{Se}_{60.0}$ & 1.77 & 1.66 & 2.64 & 0.03 & 0.01 \\
\hline 14 & $\mathrm{Ge}_{23.3} \mathrm{Sb}_{16.0} \mathrm{Se}_{60.7}$ & 1.75 & 1.65 & 2.68 & 0.02 & 0.02 \\
\hline 15 & $\mathrm{Ge}_{11.2} \mathrm{Sb}_{28.4} \mathrm{Se}_{60.4}$ & 1.63 & 1.56 & 2.92 & 0.01 & -0.02 \\
\hline 16 & $\mathrm{Ge}_{3.0} \mathrm{Sb}_{36.3} \mathrm{Se}_{60.7}$ & 1.45 & 1.39 & 3.19 & 0.01 & 0.05 \\
\hline
\end{tabular}



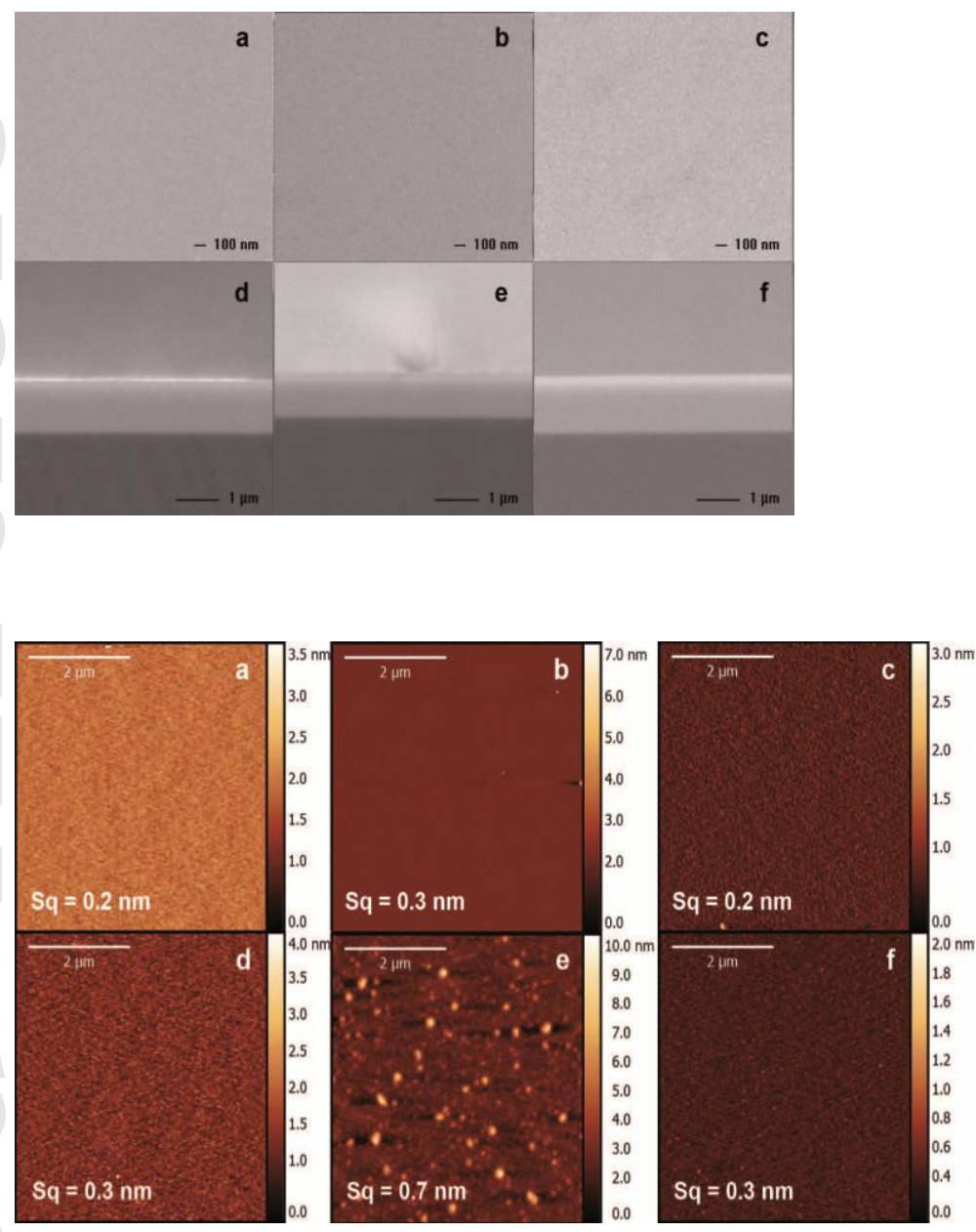

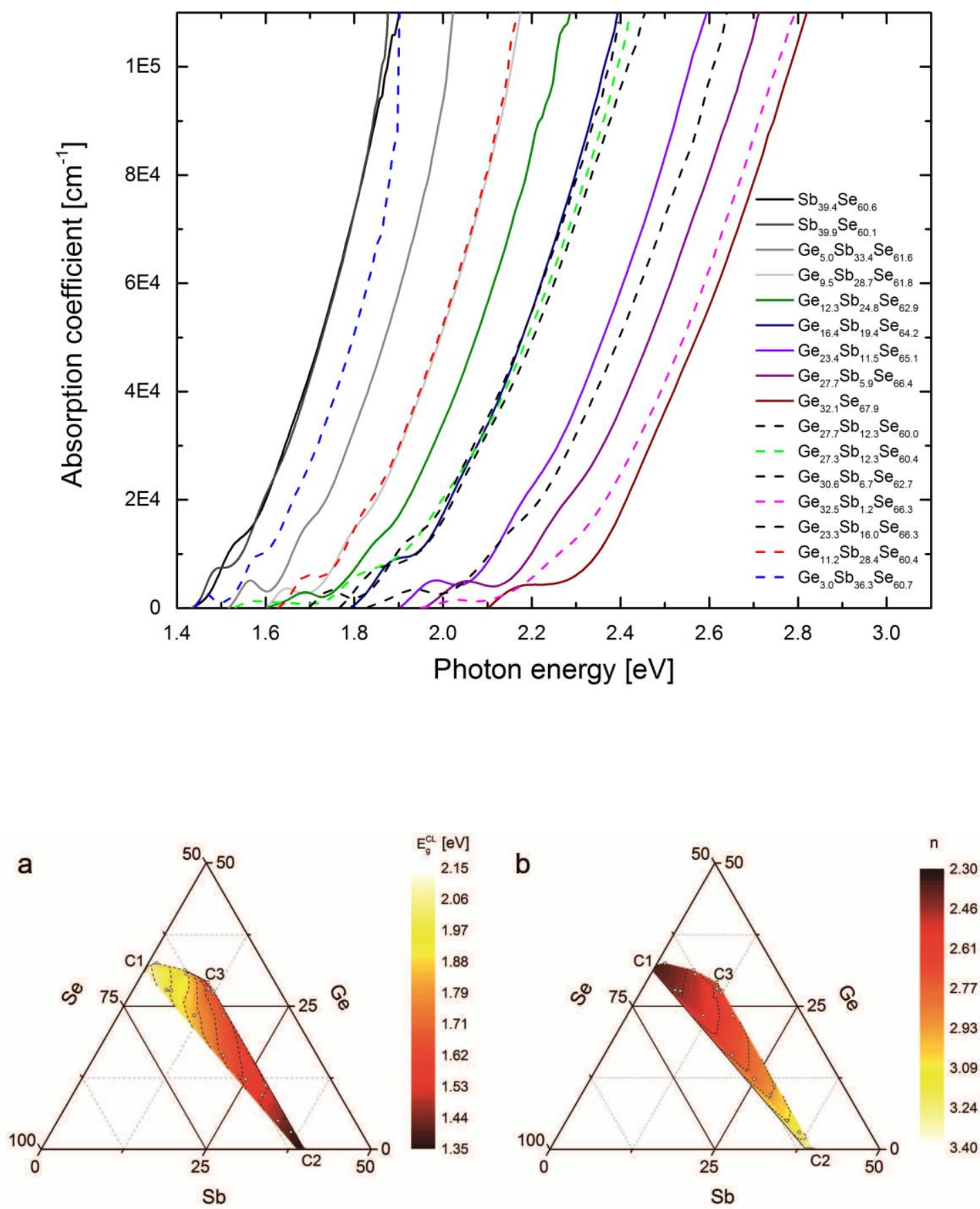

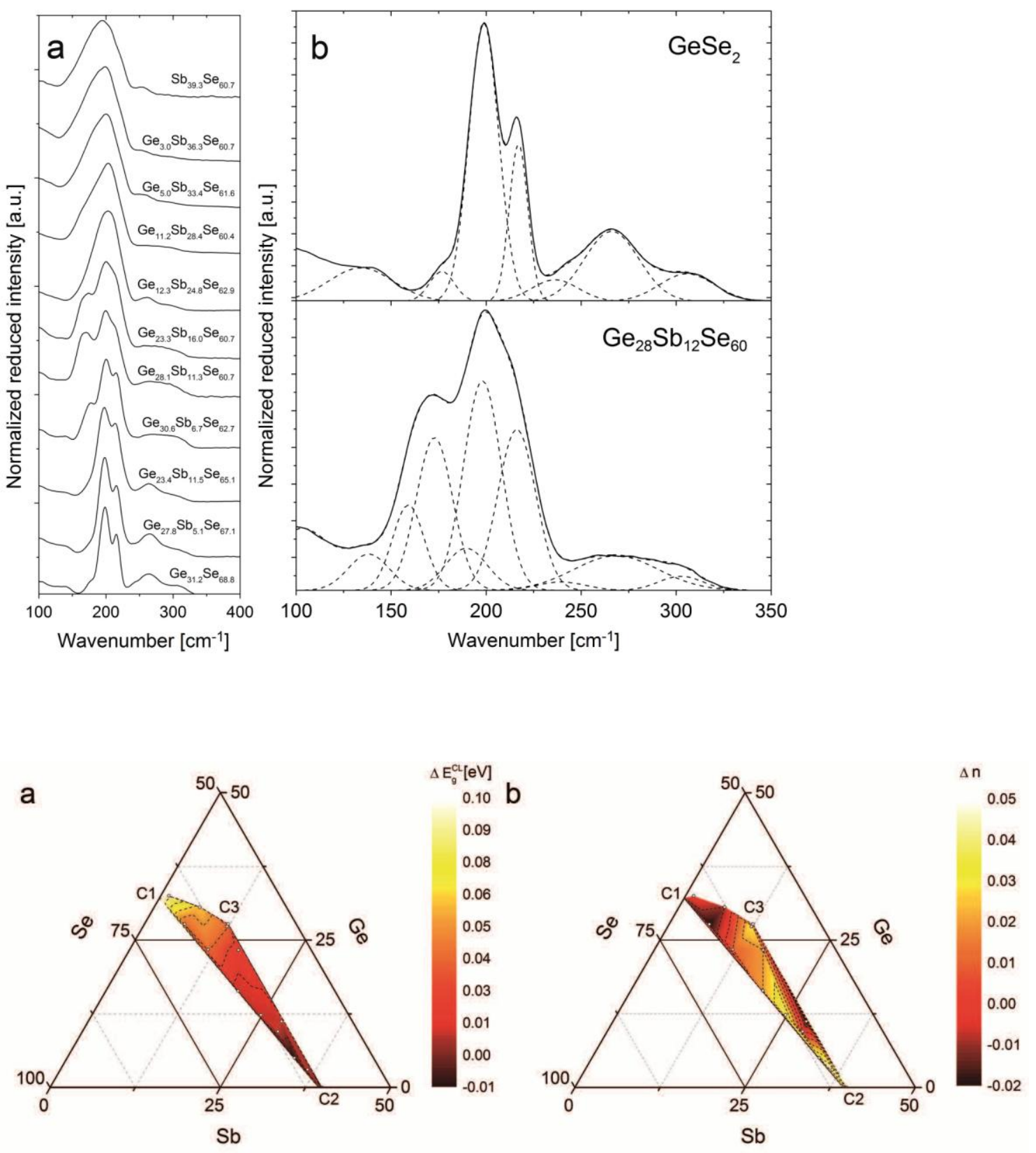


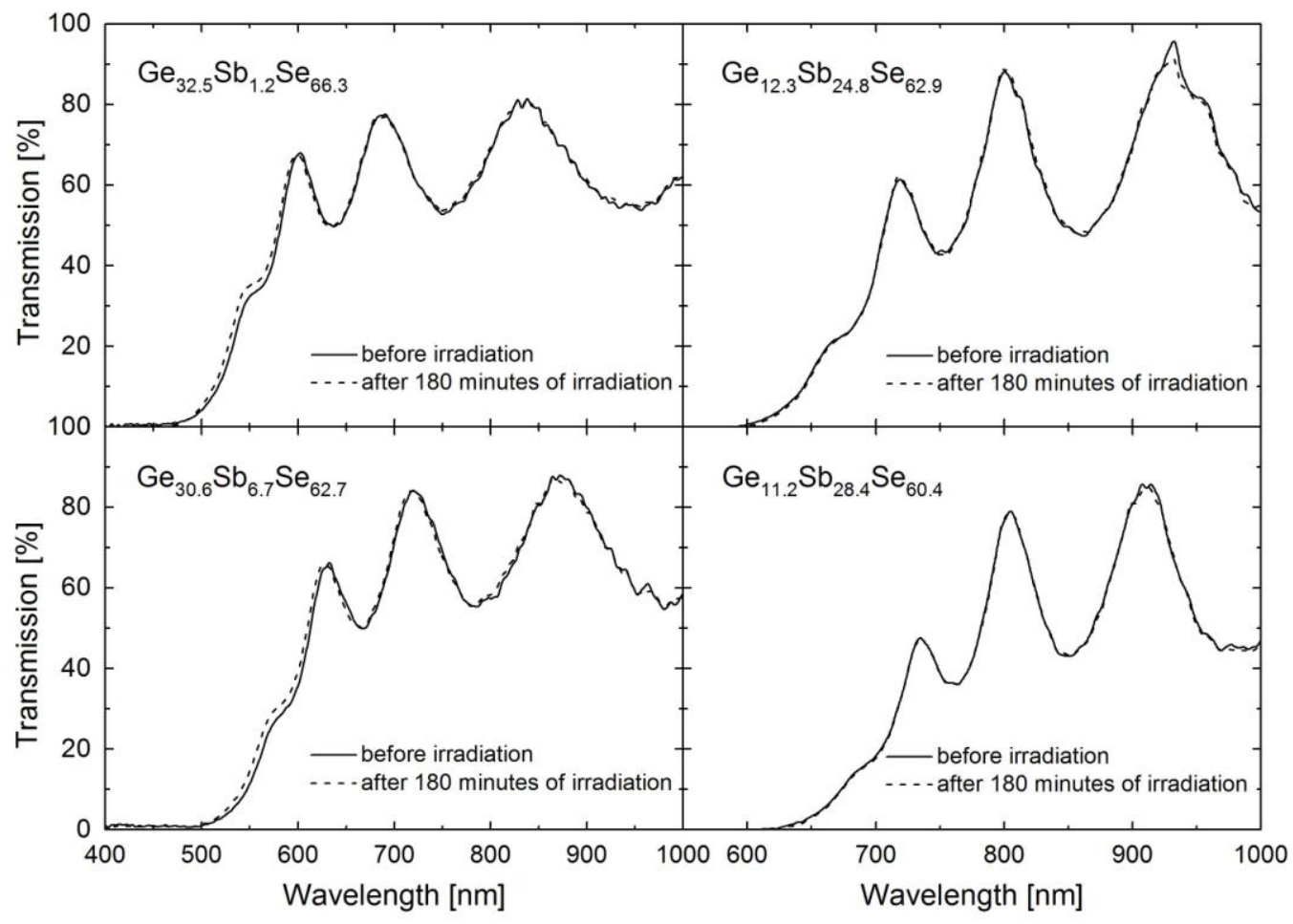




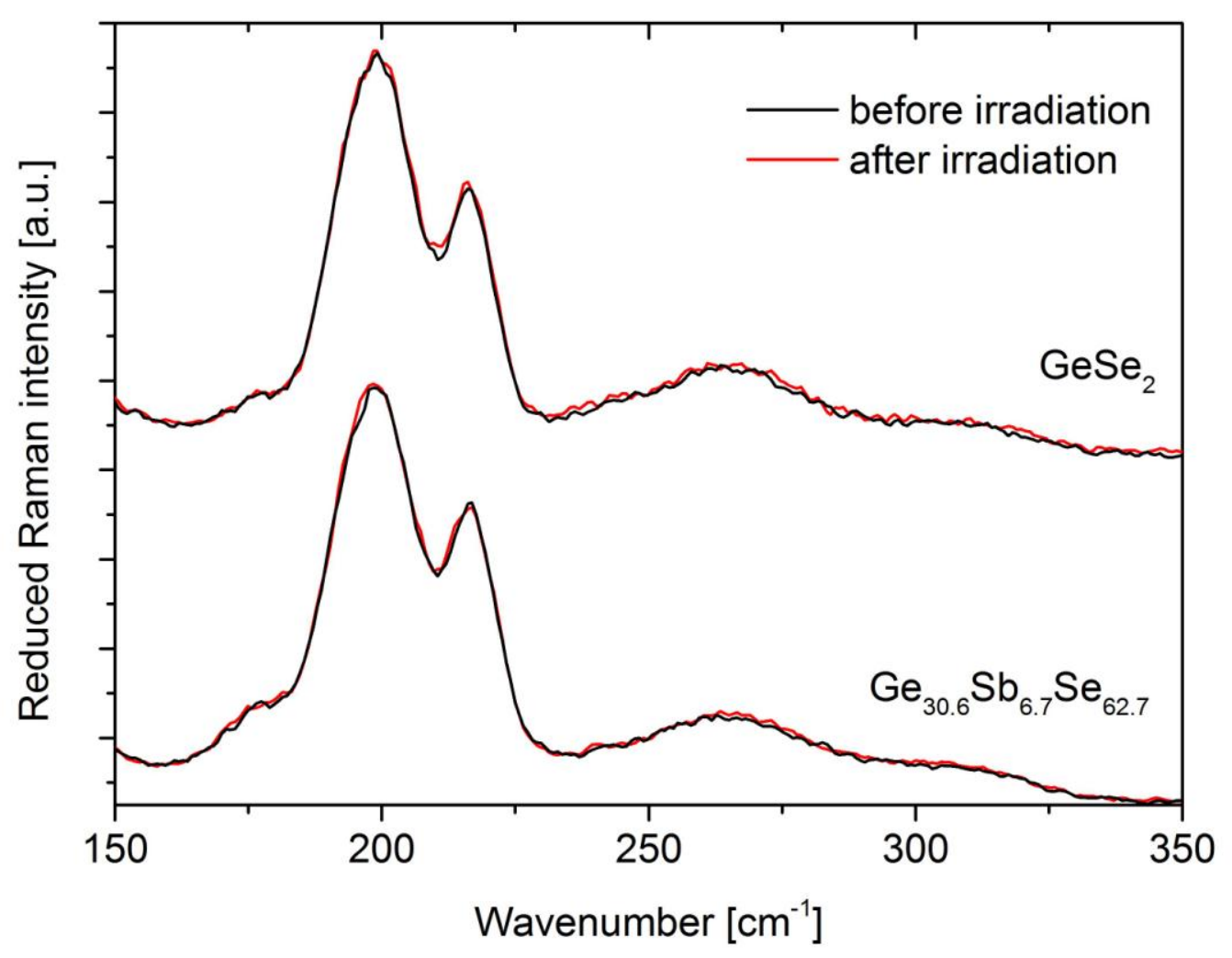

